\title{
USING POPULAR EDUCATION GROUPS: CAN WE DEVELOP A HEALTH PROMOTIONS STRATEGY FOR PSYCHIATRIC CONSUMERS/SURVIVORS?
}

\author{
LEA CARAGATA \\ Wilfrid Laurier University
}

\begin{abstract}
It is widely acknowledged that health derives from a myriad of factors including economics, education, housing, and social support (Sidell et al., 1997). In short, health care, although dominant in North America, represents only one approach to health.

The paper suggests utilizing the theory of Paulo Freire (1971) conceming adult and popular education to support the empowerment of psychiatric consumers/survivors with regard to their health. The paper theorizes that, as psychiatric consumers are supported to 'own' their health through a process of mutual aid, they will be more able to become partners in managing not only their psychiatric illness but their health. The paper argues that it is incumbent upon traditional mental health services as well as community innovators to undertake these facilitative roles.

More generally, the paper suggests that a health promotions/health determinants approach can be efficacious in improving the health of other high-risk/highuse health care groups, and that we must direct concerted efforts to reduce the marginalization experienced by so many of our citizens.
\end{abstract}

\section{INTRODUCTION}

In Canada, many traditional approaches to health and health care have been challenged. We recently have witnessed a legitimizing by western science of acupuncture, herbal remedies, and a host of other interventions which previously had been discounted. As well, the burgeoning research on determinants of health has raised important questions about our focus (both in policy and social spending) on medical care which may have overshadowed other factors equally determinative of health. While our thinking about health and health care has been challenged, there is less evidence of change in health and medical care practices, especially in the field of community mental health. Questions about what we know and who knows what, with regard to health and health care, are beginning to emerge (Trainor, Pomeroy, \& Pape, 1997) and these presage changes in health care practice.

Psychiatric consumers/survivors seem a group for whom the importance of new knowledge and new ways of thinking about what we know will be highly relevant.

I would like to express my appreciation to Dr. Richard Walsh-Bowers for suggesting this isue as important for inquiry and for his contribution to this work. 
Recent research on health determinants is illustrative. Psychiatric consumers/survivors are highly involved in the health care system and yet experience, overall, less good health than does the population as a whole (Lieberman \& Test, 1987; Byme, Isaacs. \& Voorberg, 1991), in spite of the absence of any determinative physical health conditions which would explain these differences.

This paper explores and links two discrete conceptual and theoretical works and suggests that, in combination, they may be important to community mental health practitioners and to psychiatric consumers/survivors. The theoretical work of Paulo Freire (1971) describes a process of personal and political empowerment using a model of popular education which he developed. This paper suggests the relevance of Freire's notion of "conscientizing" (as Freire describes the outcome for a participant in a popular education group) to psychiatric consumers/survivors with regard to their health. Although our expanding knowledge of health promotions and determinants has been widely disseminated, it has not changed our health care practices. A health promotions/determinants approach is largely untried, yet appears likely to be of value for psychiatric consumers/survivors. Two significant reasons care users usually pay only minimal attention to other factors which are of significalth a loss of autonomy and personal power (Byrne et al.,1991), factors which are themselves associated with less good health outcomes. Both of these issues-less good health and loss of autonomy or becoming disempowered-apply to many psychiatric consumers/survivors.

This paper discusses these issues, introduces Friere's model of popular education, and outlines in general terms how these two issues might be integrated in practice with psychiatric consumers/survivors. Importantly, the approach suggested is consistent with the values of the psychiatric consumer/survivor movement with regard to promoting increased autonomy and self-reliance.

The paper suggests that a process of conscientizing psychiatric consumers/ survivors about their health and its determinants may: (a) improve participant selfesteem and well-being. (b) facilitate participant self-awareness and reflection, and (c) increase participant social networks and personal resources. Beyond these individual outcomes, this paper and previous research suggest that interventions of this type will support the following social or systemic outcomes: (a) expanded health partnerships wherein patients become equal members of the treatment planning team, in turn improving health outcomes; (b) increased autonomy and personal responsibility for health management; and (c) political and social action by participants, arising from their expanded awareness and oriented to improving the "system's" responsiveness to their needs.

A brief note about terminology and underlying values is necessary. The term "psychiatric consumer/survivor" is used throughout this paper to refer to a population variously described by others with terms such as "the seriously mentally ill" or "chronic psychiatric patients." Consumer/survivor is, however, the term by which these individuals most often choose to refer to themselves, and I use it here to respect this right to self-identification. Further, the term "health" is used in juxtaposition to "medical care"- they are not synonymous and, throughout, I use health to refer more broadly to physical and mental health and well-being, as it has been defined by the 
UN and in the population and community-health literature (Sidell et al., 1997; Evans, Barer, \& Marmor, 1994; Nettleton \& Bunton, 1995).

\section{PSYCHIATRIC CONSUMERS/SURVIVORS AND DETERMINANTS OF HEALTH}

The policies of the World Health Organization (WHO) and most national governments acknowledge that the bealth of the world's population derives from many factors, including economics, education, housing, and social support (Sidell et al., 1997). In short, medical care, although the dominant health strategy utilized in North America, represents only one approach to health.

Vulnerable populations, including psychiatric consumers/survivors, are less healthy, and consume services and care at high rates which do not translate into improved health (Lieberman \& Test, 1987). Health care agendas are often imposed on vulnerable or marginalized groups (Douglas, 1997). This implication increases passivity and feelings of powerlessness which are further associated with poor health outcomes. In contrast, feeling empowered has been found to promote positive health outcomes (Caldwell \& Caldwell, 1991).

Especially in the western world, more and more citizens utilize psychiatric services. (Estimates suggest that one person in ten is likely to experience a significant mental bealth problem.) In spite of increasing demand, mental health services remain unequally available, and this situation is especially true with respect to a host of innovative services that generally can be found only in large cities (Monroe-Blum, Boyle, Offord, \& Kates, 1989; Beiser, Kuldip, \& Edwards, 1993). Psychiatric consumers/survivors represent a growing percentage of those who are incarcerated and who use hostels and shelters. They are more likely to be poor and to have more limited social networks. For those who are able to work, jobs are increasingly rare.

In considering the outlook for the psychiatric consumer, a number of factors emerge. Mental health care is an important area of public policy, representing a sizeable public expenditure and impacting on a significant percentage of the population. However, depite the significance of the issue, our range of interventions are surprisingly limited. Medical or health services for psychiatric consumers/survivors in Canada and in the US consist primarily of the administration of psychotropic medications with psychiatric out-patient follow-up. In-patient treatment periodically is required to adjust the patient's medication regimen (Harris, Hilton, \& Rice, 1993; Arling, Ryther, Collins, \& Zimmerman, 1991). Drug treatment has replaced long-term hospitalization and various forms of psychotherapy, and often is the only treatment available to persons with a chronic psychiatric problem (Harris et al., 1993). These medical interventions are augmented by other forms of care-usually community based and non-medical in nature- of variable availability, type, and quality and not necessarily integrated with other medical interventions.

In Canada and the US, the notion that mental health care: (a) should focus on the needs of the seriously mentally ill; (b) requires the co-ordination of community and institutional services; and (c) should employ a partnership between service providers, mental health consumers/survivors, and their families (Macnaughton, 1992) is increasingly embraced. In short, mental health care must go beyond medical care and its provision by the health-care community. This work supports this view, including the policy perspective endorsed by several Canadian provinces, that "consumers ... 
can and should play an active part in their own recovery" (Macnaughton, 1992, p.10). Trainor and Tremblay (1992) refer to this development as the trend away from a service mentality toward an acknowledgement that serving the needs of persons with chronic mental health problems involves more than the provision of traditional health care. Although this position seemingly is accepted in policy terms, there is little evidence of its incorporation by health and service providers. There also is limited research which explores the relationship between health services and other more social determinants of health for this and other vulnerable populations.

The need for further exploration of alternative and empowering treatment or response models derives from several factors, including the inadequacy of current mental health services in meeting the needs of psychiatric consumers/survivors and the fiscal constraints which likely will preclude the continued expansion of these services. An alternate response is required-a response which avoids the US circumstance which increasingly finds the correctional system serving to contain those with mental health problems. (Between 10 and $35 \%$ of a burgeoning US prison population are estimated to be mentally ill (Severson, 1994).) Effective development of alternatives requires an improved understanding of how the determinants of health discussed here actually play out in the lives of psychiatric consumers/survivors.

The condition of psychiatric consumers/survivors is only in part related to their psychiatric problems and resultant symptomatology (Aviram, 1990), and yet their care has been dominated by the medical profession, with its emphasis on curative medicine and a desire to retain its leadership position in mental health treatment and care (Conard \& Schneider, 1985). This medicalization of mental health problems further results in high levels of public expenditures being directed to acute hospital care rather than to providing services required by those who are characterized as being chronically mentally ill (Aviram, 1990). Across Canadian jurisdictions, the bulk of funding has been allocated to the costs of hospitalization and remuneration for physicians, while community treatment has received a minuscule proportion of available monies (Pape \& Church, 1987; Macnaughton, 1992).

Health care utilization for psychiatric consumers/survivors is high, yet it is not highly effective at enabling them to maintain "normal" life functioning. While the utilization of health services and their efficacy is very likely impacted by many other factors which determine the health of psychiatric consumers/survivors, attention to these other factors has not become a priority. As the data on feelings of agency or empowerment (Saraceno \& Barbui, 1997; Caldwell \& Caldwell, 1991) emphasize, the very experience of acting as a partner in one's own health is likely to have a positive therapeutic outcome. Maximizing the efficacy of health service use depends on understanding its relation to these other factors which also determine health outcomes. The effectiveness of our medicalized approach to mental health care is perhaps best considered by reflecting on a 1979 study done by the WHO. Researchers found that persons diagnosed as having schizophrenia had better outcomes if they lived in developing countries compared to those in developed countries. In developing countries, patients were found to return more readily to their productive roles and were more likely to be supported by extended families and their local community. Another perspective suggested that services in developing countries were more effective, less focused on material resources, and more oriented to the patient's integration in the community, comprehensiveness, intersectoriality, and a different "style of work." These findings are a compelling example of the power of social determinants to shape health outcomes, yet they apparently are ignored by western experts who fail to sec 
the relevance of this finding for community mental health practice in the so-called developed world.

Psychiatric consumers/survivors frequently are homeless; estimates suggest that they comprise $30-40 \%$ of the homeless in the US (Lamb, 1984; Rossi, 1987). Canadian data are likely similar. A recent Toronto study of hostel users found that 70 $80 \%$ of homeless women over 50 had severe mental health problems and, in general, $66 \%$ of the homeless population had a mental health diagnosis (Springer, Mars, \& Dennison, 1998). Homelessness for the psychiatric consumer occurs, in part, because housing providers (market and non-market) evidence a preference for more "normal" individuals (Boyer, 1987; Page, 1980). Only a small proportion of psychiatric consumers/survivors is served by non-profit housing. A recent study done by Caragata and Hardie (1998) found psychiatric consumers/survivors to be significantly underrepresented on waiting lists for social housing given their representation among the homeless population. Psychiatric consumers/survivors are more likely to become homeless and face greater obstacles in escaping this circumstance.

Psychiatric consumers/survivors, like other groups of persons with a significant disability or disease, face an increased risk of poor health-not because of their primary health issue, but arising from the low socio-economic status which is usually associated with disability (Thiede \& Traub, 1997; Haggarty \& Johnson, 1996). The low socio-economic status of psychiatric consumers/survivors derives in part from lower educational attainment and this, in turn, affects both employment and income. Canadian scholars have argued that a structural reason for the social and economic marginalization of persons with disabilities is a tacit social policy that links disability with living well below any poverty line (Rioux \& Crawford, 1990). Thus, the level of poverty experienced by psychiatric consumers/survivors is, by itself, a major determinant of their poor health outcomes.

Wellman $(1979,1983)$ notes that social networks are important sources of the contacts that often facilitate employment, while Gotring et al. (1992) note that psychiatric consumers/survivors are alienated from their networks of support. Social support is acknowledged as an important determinant of health in general (Whelan, 1993) and is especially at issue for psychiatric consumers/survivors (Nelson, Hall, Squire, \& Walsh-Bowers, 1992). Psychiatric hospitalization disrupts relationships with families and friends, often because it involves moving patients from their own community. Furthermore, the limited availability of psychiatric outpatient services frequently dictates that the mental health client remain in the new community in order to be able to access services after discharge. For example, relations with the family of origin, which remain significant in most people's social networks (Wellman \& Wortley, 1988), are usually strained by the psychiatric episode that triggered the treatment intervention (Hatfield, 1987; Spaniol \& Zipple, 1986). The social isolation, lack of job, and insufficient income that follow from a prolonged hospitalization and/or identification as a "mental patient" further reduce psychiatric survivors' opportunity to build a stable and supportive social network (Wellman, 1979. 1983).

The small body of literature that addresses the health of psychiatric survivors shows that they tend to differ from the general population both in terms of physical health status and knowledge of how to care for their own health (e.g., Lieberman \& Test, 1987). In an Ontario study, Byrne et al. (1991) found that participants in the sample were more overweight, consumed more caffeinated coffee, smoked cigarettes more heavily, and participated far less in any exercise regime than the general 


\section{CANADIAN JOURNAL OF COMMUNTTY MENTAL HEALTH}

Canadian population; on the other hand, the survivors were much less likely to consume alcoholic beverages, perhaps because they could not afford them. In a US study, Lieberman and Test (1987) observed that, when health services were offered to consumers/survivors in the supportive context of comprehensive community-based treatment, survivors made as much use of the medical and dental care opportunities as did the general public. This latter study suggests that, when appropriately supported, psychiatric consumers/ survivors take initiative and responsibility for their health.

Coincident with medicalized practices for psychiatric consumers/survivors are widespread beliefs about the presumed limitations and deficiencies of these individuals. Common notions are that chronic patients inevitably will deteriorate as they age, and their capacities for relationships and employment are meagre (e.g., Hodgins, 1996). Adherents to this perspective tend to neglect the social conditions that impinge upon psychiatric consumers'/survivors' attempts to develop their competencies and also fail to recognize the evidence from long-term follow-up studies that show the possibilities for recovery and improvement (e.g., Harding. 1991). Consumers/ survivors themselves often perceive their circumstances quite differently than do professionals (Dulac, Mongeon, \& Tempier, 1988), contending that they can become as stable as other citizens, as long as they have access to a web of informal and formal support systems (Burstow \& Weitz, 1988).

Given that health and health outcomes are affected by income (poverty), employment, housing, social support, and environmental factors (Evans et al., 1994; Nettleton \& Bunton, 1995), the health status of psychiatric consumers/survivors is compromised by their impoverished circumstances. Relatedly, psychiatric consumers/ survivors are socially marginalized and stigmatized by Canadian society at large and by mental health professionals (Dulac et al., 1988; Page \& Day, 1990).

The reflections and suggestions for intervention which follow are based on the findings of the preceding review (i.e., that, although significant social spending is directed to psychiatric consumers, rather than improving their health and well-being we seem to be in a spiral where traditional medical interventions are associated with both dependency and resistance among psychiatric consumers/survivors with respect to their health care). Many psychiatric consumers/survivors refuse medication and, whether such refusal is, as is often claimed, symptomatic of their illness or not, it is quite apparent that we bave not found effective methods at a population level of maintaining the health and personal autonomy of psychiatric consumers/survivors. This is a population marginalized and alienated from much of mainstream life. Both in-patient and community psychiatric care, as they are commonly structured, tend to disempower the consumer (Townsend, 1998), often neglecting the concrete circumstances of daily living that impact on health and well-being.

Overall, a number of elements in the life circumstances of psychiatric consumers/ survivors further contribute to their poor bealth and perhaps to their chronicity. Poverty, low educational attainment, and social networks are each independently determinants of health and clearly are important factors in the lives of psychiatric consumers/survivors. These issues generally are seen to be inescapably related to the psychiatric problem, or even deriving from it. While an expectation of diminished capacity in some areas may not be unreasonable, as Rioux and Crawford (1990) argue, poverty is simply presumed to accompany disability and it need not. As a society, we might make other choices which would ensure an adequate income to 
those with disabilities. Poverty and homelessness are two other obvious conditions which could be ameliorated through public intervention. As well, the rights and autonomy of psychiatric consumers/survivors are further eroded through an increasingly singular role-identity as patient. Psychiatric consumers/survivors are less likely than others to be active in the roles of neighbour, family member, employee, or student. Since being a patient is coincident with medicalized control of one's health, the ability to express agency, to be an actor in one's own life, is also lost. When patient becomes the only, or the primary, identity role-as often happens with marginalized and chronic populations - this medicalized control and its pervasiveness serve to further marginalize and disempower. This often is the experience of psychiatric consumers/survivors.

\section{Empowerment as a Determinant of Health}

A large and growing literature acknowledges that, in all areas of health care (including mental health), care is more efficacious if the patient or consumer is involved as a partner (Caldwell \& Caldwell, 1991). Nonetheless, a partnership approach is far from the norm in providing health services to psychiatric consumers/survivors. Rather, paternalistic practice often predominates in the form of case management models that, in effect, bolster the operation of existing mental health systems (WalshBowers \& Nelson, 1993; Townsend, 1998). There are, of course, some notable and exceptional programs which foster consumer/survivor self-reliance and autonomy, which will be discussed later.

Treatment is more likely to be efficacious when both parties become more involved in treatment decisions. Consumers/survivors are more likely to appraise and report on the effects of interventions if they believe that their feedback will be respectfully received. Further, the process of such treatment partnerships is, in itself, likely to have a positive impact, contributing to the consumers'/survivors' view of themselves as responsible for, or managing, their own health. Recent clinical trials confirm the significance of the relationship between empowering patients and their health outcomes. Treatment was found to be more effective when patients had various opportunities to manifest their control over the treatment setting (Saraceno \& Barbui, 1997).

The typical medical care provided to psychiatric consumers/survivors systematically ignores what we know about determinants of health. Considering research which evidences empowerment as a further determinant of health completes a picture whereby one, albeit significant, health issue effectively reduces the people affected to "patients" who consequently can expect poor health outcomes in every other area. Effective interventions must reach beyond a narrow understanding of health, must be holistic, and must be both personally and politically transformative. They necessarily must address issues such as the loss of personal autonomy and self-regard and the sense of being an actor in one's own life and health.

\section{A MODEL OF POPULAR EDUCATION OR CONSCIENTIZATION}

Paulo Freire (1971) is credited with creating and popularizing the popular education movement in Latin America and certainly with increasing its visibility in North America. He has written extensively about a process of personal and social change which derives from participation in a popular education group. While "conscientization" and popular education have become well known outside of Latin 
America, these techniques more frequently have been adopted by grass-roots organizers than by social workers and health care professionals. Nelson, Ochocka, Griffin, and Lord (1998) acknowledge the importance of Friere's work to the development of participatory action research, which they advocate using with psychiatric consumers/survivors because it supports critical analysis and organized action. Participatory action research is an outcome of this same popular education process; thus, the values which appealed to Nelson et al. (1998) for work with psychiatric consumers/survivors apply equally here. Friere developed an approach to overcoming oppression-in his context the oppression usually was economic and political. The oppression experienced by psychiatric consumers/survivors might be claimed to be different in substance: it is not intentional, perhaps it even develops as a result of the good intentions and caring offered by our traditional medical care system. Nonetheless, oppression does describe the economic and social impoverishment, the reduced social roles, and the diminished sense of personal power experienced by psychiatric consumers.

Conscientization is the translated word used to describe both the process and outcome for the individual participants involved in popular education groups. Freire describes a group process which brings together members of a community or group of people who share a particular circumstance, generally one of social and/or political alienation. The concept is that "people develop awareness of themselves, their environment and that from which they are alienated" (Freire, as cited in Poertner, 1994, p. 267). Overcoming oppression and/or alienation is based upon generating culturally or group-specific knowledge about its form, and upon understanding its causes, effects, and solutions. Popular education begins with: (a) a critical examination of social and interpersonal patterns of behaviour and acculturation, and (b) an experience of co-operative learning as group members learn from one another. These processes serve as a basis for deeper learning from which personal autonomy and responsibility develop, leading in turn to a group-directed outcome-often community or social action.

While popular education was developed as a process to effect political change, the change process which results can be understood more broadly as one of personal and social transformation-changing structures, relations, institutions, and patterns which reinforce a particular social or socially understood way of being in the world. Considered in this way, the usefulness of a conscientizing process for any marginalized population becomes apparent. Through a supported group process, participants come to see themselves against the social, political, and economic backdrop which is their society. They begin to have a reflective awareness of the forces out of which their identities have been constructed (personal liberation or empowerment) and how they might act to change these (social and political transformation). It has been argued that the process of conscientization may be readily adopted by social workers as a potentially empowering adjunct to traditional clinical practice (Caragata, 1997) and, in this same vein, this paper proposes its suitability for community-based work with psychiatric consumers/survivors.

\section{Building on Innovation}

Much innovative work already occurs within the community mental health field (Carling, 1995). Many of these innovations have been led by psychiatric consumers/ survivors themselves as they have realized the shortfalls in the traditional medical approach to their care (Chamberlin, 1995: Trainor \& Tremblay, 1992). Community 
practitioners often have supported self-help movements and have initiated new community-based programs which foster elements of self-help as an integral part of the programs they run. Two such models include Club Houses (such as Fountain House in New York and others developed along similar lines across North America) and psycho-social rehabilitation programs, also widely available. In spite of their strengths, professionally run community mental health programs evidence problems such as a continued narrow focus on symptom management and on the development of social skills (Wilson, Flanagan, \& Rynders, 1999) at the expense of other more generic skill development and support. Wilson et al. (1999) also report on a professionally facilitated mutual-support program which is perhaps a manifestation of partnership-combining the autonomy afforded by a self-help approach augmented by the skills which professionals can offer. Townsend (1998) also contributes to the discourse of dependence/empowerment, offering a detailed and thoughtful analysis of why so many well-intentioned professional interventions fail to contribute to empowered clients. A problem that continually arises, even with more innovative programs, is that professional involvement often leads to professional domination. And, however effective these alternative programs are, often the most traditional medicalized services to psychiatric consumers/survivors remain largely unchanged. Carling (1995) provides an excellent summary of what often has been consumer-led innovation and the challenges associated with fundamental system change.

Trainor, Pomeroy, and Pape (1997) contribute to our understanding with respect to the lack of a shared mental health epistemology by outlining the kinds of knowledge which each of the parties involved in the mental health system usually brings to the table. Their work is significant because it avoids the usual problem of rejecting one paradigm in favour of an alternate. They suggest, in keeping with the models of partnership discussed here, a valuing of the different kinds of knowing which each of the parties can contribute. The biggest challenge with such a proposal continues to be supporting the voices of consumers and offering a sufficiently compelling reason why traditional medical practitioners should listen.

This work is intended to build on the directions taken by these innovations and to contribute a way of thinking about how we can enable the (louder) voices of consumers, and perhaps even engage the medical community in listening. Proposed is not something revolutionary, or even a new model; rather, it is a consideration of work from elsewhere in the world and an appreciation for its relevance in this context. Although Freire's (1971) work may not be familiar to community health practitioners, it is widely utilized in Latin America, has influenced North American community development, and is argued to be highly relevant to social work practice (Poertner. 1994). Mental health scholarship increasingly recognizes the relevance of his work (Carling, 1995; Townsend, 1998), although the translation of this acknowledgement into practice remains incomplete. The goal of this paper is to suggest the usefulness of applying the popular education process to what we know about determinants of health.

The process described here most likely will appeal to psychiatric consumers/ survivors and community mental health practitioners already persuaded to work on issues of empowerment; however, it also has relevance within a hospital setting. especially with outpatient support groups. As Salzer (1997) notes, obstacles continue to impede the promotion of consumer empowerment, among them a requisite change in role relationships so that "consumers are viewed and treated as colleagues and 
collaborators rather than passive recipients" (p. 430). The involvement of hospital staff in facilitating a popular education process might be an important first step toward partnership and collaboration.

\section{Implications for Social Work and Community Practice}

I suggest that the principles of popular education can be usefully employed with psychiatric consumers/survivors in a group process from the perspective of health determinants/promotion. A facilitated, mutual-aid model is aimed at both enabling the participants to own the process and recognizing the need for the provision of information and facilitation.

Group work is of longstanding importance in work with psychiatric consumers/ survivors. Treatment groups in hospital settings and support and self-help groups facilitated by community practitioners have a long, successful North American history. For psychiatric consumers/survivors who face issues such as low levels of self-esteem, marginalization, and reduced social networks, groups are an obvious choice as a vehicle for a health promotions process-especially given that many determinants of health relate to issues of personal and social connectedness. A popular education group process is not intended to minimize the significance for psychiatric consumers/survivors of behavioural issues or individual pathology; rather, the goal is to acknowledge that these issues remain only one part of the person and that even these issues are constructed in a social context.

Freire's (1971) model of popular education groups could be readily adapted to a facilitated mutual-aid group process of exploring health impacts and outcomes for psychiatric consumers/survivors. Such a process might expand participants' selfawareness and competence with regard to their own health by providing information and social support and by enabling consumers/survivors to become more empowered about their health and well-being.

Thus, the outcome of such a process would be individual change: reflexive understanding, expanded personal competence, and a re-awakened belief that one's health is determined by other factors beyond medical care. Being a chronic health care user does not have to mean a relegation to a perpetual and singular role as patient. A further outcome would be expected to encompass some kind of action, the nature of which would be determined through the facilitated group process but may include actions specific to the experience of those group members (i.e., inviting the members of their social networks, therapists, and doctors to a discussion or organizing an ongoing support group), or it may be more overtly political (i.e., connecting with consumer initiatives or advocating for a health-promotions approach in treatment). Whatever the action, it must be related to the resources, needs, interests, and capabilities of the group; it must be something on which the participants want to work.

An effective popular education process must be sufficiently intense to provide the members an opportunity to develop trust, to explore and assimilate the ideas and issues discussed, and to assess their health and heath impacts over time. Furthermorc, in ongoing groups, consistent membership is essential to establishing the levels of trust necessary for open discussion and disclosure. This approach is suited to providing opportunities for the voices of this marginalized population to be heard (Lord, Schnarr, \& Hutchison, 1987) and for interchange and learning between members. As well, groups have been shown to stimulate their members to reflect on and discuss a broader array of issues than can sometimes be generated in an individual 
setting (Krueger, 1994; Morgan, 1997). Through facilitation, these experiences can lead to self-reflection, which is an essential component of the conscientizing process described by Freire (1971). Constructing the groups with regard for similarity of circumstance/homogeneity (such as degree of illness, life circumstance, in-patient status, gender, etc.) would be likely to facilitate group cohesion. Group members ideally would assist in setting topics, but the group sessions would be focused generally on participants' health, health experiences, and health practices and would attend to factors which support feclings of well-being, social networks, and employment. Through these broad explorations, the group defines its own culture and focus, and engages in the process of reflection and critical appraisal described here. In short, at some stage, the group begins to act on its own-to devise its own version of this agenda. Identifying the ways in which group members might experience alienation and what they might do in response is the beginning of the conscientizing process. It is important to note that the process which I am suggesting, building on Freire's work, is both cognitive and relational. Thus, some consumers/survivors-because of illness, side-effects, or other issues-may have difficulty in participating fully in such a process.

\section{BRINGING THESE ISSUES TOGETHER: POPULAR EDUCATION AS A TOOL FOR HEALTH PROMOTION}

Popular education, or the process of conscientization, is akin to some of the selfhelp processes already being utilized by psychiatric consumer/survivor groups. However, the critical issue is that there remain two solitudes-psychiatric consumers/ survivors and their organizations, and a largely unchanged formal mental health system. In the middle, and perhaps active in brokering between these two worlds, are community-based initiatives which value consumer autonomy. These organizations likely are responsible for an important advance in the legitimization of psychiatric consumer/survivor groups by mainstream health service organizations. Nonetheless, medical care organizations remain firmly at the helm with respect to the health and medical care provided to this population. Rather than the very positive advances in the consumer movement changing traditional mental health care, the response of the medical care establishment appears to be community treatment orders or "assertive community treatment." Salzer, McFadden, and Rappaport (1994) use the term "professional-centrism" to describe the belief that professional services are the base of an effective mental health system. They further suggest that it is just such a belief that inhibits the professional support of mutual-aid groups (Salzer \& Rappaport, 1995, as cited in Salzer, 1997). Emerick supports the contribution that professionals can make to such processes, but adds the necessary caution that they must endorse the "self help values of independence, empowerment, conscious raising, and mutual aid" $(1990$, p. 406). I suggest that professionals, with their knowledge of health determinants and health, are potentially well situated to facilitate a non-medical intervention aimed at health promotion. They have the necessary skills to support the reflexive self awareness necessary to personal empowerment-providing, of course, that they also subscribe to the values which Emerick (1990) identifies.

Nurses, hospital social workers, and community workers are ideally situated to facilitate a mutual-aid process which acknowledges the needs and poor health outcomes of psychiatric consumers/survivors. This acknowledgement, in turn, suggests that both individual and social change are required in order to transform the 
experience and circumstance of this population in any substantial way. A popular education process may be an important first step in building the partnerships which are often referenced as ideal but seldom found.

\section{Translating Ideas into Practice}

While the specific approach suggested here is untested, it builds upon experience working in mutual-aid settings with this population and, more recently, upon focus groups used as a research tool with homeless people, including psychiatric consumers/ survivors (Caragata \& Hardie, 1998). In this latter endeavour, when appropriately facilitated, we found that group members moved very quickly from relating to us as the researchers to engaging with one another. The groups shared information, reflected on, and responded to one another's experiences and, in one case, agreed to act together beyond the focus group on a particular lobbying effort which was of mutual interest. This experience is further evidence of the conscientizing power of groups, when the professionals facilitating them enable group members to understand their own situation and support the development of participants' awareness of the need for change.

As psychiatric consumers/survivors are empowered to own their own health, through information, reflection, and supported sharing in dialogue with their peers (a process of mutual aid), they can become partners in managing not only their psychiatric illness, but also their health. A conscientizing approach facilitates this growth, builds trust through shared experience, gives voice through the recording of these experiences, and develops self- and social-reflection, which are key elements of conscientization. I have suggested that the outcome of such a process is a much more familiar concept, that of empowerment (Rappaport, 1987; Nelson,1998; ) And empowerment, as is frequently argued (Rappaport, 1985; Prilletensky, 1992), is both process and outcome. Ultimately, empowerment may be the route to a genuinely holistic understanding of health and to real models of partnership between doctors and patients. However, a requisite condition of health and partnership is the agency of both partners. And, of course, the benefits of empowered people extend beyond the improvement of their own health.

\section{CONCLUSION}

The marginalization of so many people in our society has been described as the making of a new "underclass" (Kaus, 1992; Shragge, 1997). This paper has outlined a strategy which promotes both the inclusion of psychiatric consumers/survivors and individual and social transformation. This same strategy may be applicable to other marginalized health care users who, in part, experience such marginalization because of treatment processes and interventions which emphasize the role of patient at the expense of other social roles and functions. In spite of what we know about the broad determinants of health, we continue to sustain a medical care system which acts as though these other determinants of health are not in their purview. This paper has argued that Freire's (1971) model of popular education would be effective in developing an approach to health promotions with psychiatric consumers/survivors. A facilitated mutual-aid process may improve the health of participants and be an important step in the consumer empowerment necessary to real partnership between those receiving care and those providing it. 
Strategies which empower involve creating and supporting a reflexive selfawareness and a collective sensibility. That collective sensibility, in turn, invokes a sense that we all benefit from a society wherein everyone has a stake, a valuable contribution to make, and the right to health as it has been broadly constructed here. It is in our collective interest to support the capacity of all of our citizens-which means not consigning those with chronic illness to a marginal place.

\section{RÉSUMÉ}

Il est généralement reconnu que l'état de santé est la résultante d'une myriade de facteurs qui incluent la situation financière, l'éducation, le logement et le soutien social (Sidell et al., 1997). En bref, bien qu'ils occupent une place dominante en Amérique du Nord, les soins de santé ne sont qu'une des approches possibles de la santé.

L'auteur de cet article suggère de mettre à contribution la théorie de Paulo Freire (1971) concernant l'éducation des adultes et l'éducation populaire pour favoriser la prise en main de leur santé par les consommateurs/survivants et les consommatrices/survivantes de la psychiatrie. L'auteur avance l'hypothèse que si l'on aide les consommatrices et les consommateurs de soins psychiatriques à prendre en charge leur propre santé, ils deviendront des partenaires non seulement dans la gestion de leur maladie mentale, mais également dans celle de leur santé. On fait valoir dans cet article que ces róles de facilitation incombent aussi bien aux services de santé mentale traditionnels qu'aux innovateurs dans la collectivité.

De façon plus générale, l'auteur laisse entendre qu'une approche fondée sur la promotion de la santé et les déterminants de la santé peut se révéler efficace pour ce qui est d'améliorer l'état de santé d'autres groupes à risque élevé qui sont de grands consommateurs et consommatrices de soins de santé. Il aftime en outre que nous devons déployer des efforts concertés pour contrer la marginalisation que connaissent bon nombre de nos concitoyennes et concitoyens,

\section{REFERENCES}

Arling. G., Ryther, B.J., Collins, T., \& Zimmerman, D. (1991). Mental illness and psychotropic medication use in the nursing home. Joumal of Aging and Health, 3(4), 455-472.

Aviram, U. (1990). Community care of the seriously mentally ill. Community Mental Health Joumal, 26(1), 69-88.

Beiser, M., Kuldip, G., \& Edwards, G. (1993). Mental health care in Canada: Is it accessible and equal? Canada's Mental Health, 4I(2), 2-6.

Boyer, C.A. (1987). Obstacles in urban housing policy. In D. Mechanic (Ed.), Improving mental health services: What the social sciences can tell us. San Francisco: Josey Bass.

Burstow, B., \& Weitz, D. (Eds.). (1988). Shrink resistant: The struggle against psychiatry in Canada. Vancouver: New/ Star Books.

Byrne, C., Isaacs, S., \& Voorberg, N. (1991). Assessment of the physical health needs of people with chronic mental illness: One focus for health promotion. Canada's Mental Health, 39(1), 7-12.

Caldwell, J.C., \& Caldwell, P. (1991). What have we learnt about the cultural, social and behavioural determinants of health? Health Transition Review, 1, 9-13.

Caragata, L. (1997). Deconstructing practice in mean times. Canadian Social Work Review, $14(2), 139-154$

Caragata, L., \& Hardie, S. (1998), An examination of the consolidated waiting lists for social housing in Toronto. Prepared for the Homelessness Action Task Force, City of Toronto.

Carling, P. J. (1995). Retum to community. New York: Guilford Press.

Chamberlin, J. (1995). Rehabilitating ourselves: The psychiatric survivor movement. International Joumal of Mental Health, 24(1), 39-46. 
Conard, P., \& Schneider, J.W. (1985), Deviance and medicalization. Columbus, OH; Merrill. Douglas, J. (1997). Health promotion strategies for black, minority and ethric communities, In N. Sidell, L. Jones, J. Katz, \& A. Peberdy (Eds.), Debates and dilemmas in promoting health (pp. 249-259). London: MacMillan.

Dulac, G., Mongeon, M., \& Tempier, R. (1988). Survey and hypotheses about promoting the mental health of persons with a history of psychiatric illness. Canada's Mental Health, 36(4), 10-13.

Emerick, R.E. (1990). Self-help groups for former patients: Relations with mental health professionals. Hospital and communiry psychiatry, 4I(4), 401-407.

Evans, R.G., Barer, M.L., \& Marmor, T.R. (1994). Why are some people healthy and others not? New York: Aldine de Guryter.

Freire, P. (1971). Pedagogy of the oppressed. New York: Seabury Press.

Goering, R., Durbin, J., Foster, R., Boyles, S., Babiak, T., \& Lancec, B. (1992). Social networks of residents in supportive housing. Community Mental Health Joumal, 28, 199 214.

Haggarty, M., \& Johnson, C.F. (1996). The social construction of the distribution of income and health. Joumal of Economic Issues, 30, 525-32.

Harding, C.M. (1991). Aging and schizophrenia: Plasticity, reversibility, and/or compensation. In E.F. Walker (Ed.), Schizophrenia: A life-course developmental perspective (pp. 257-273). San Diego, CA: Academic Press.

Harris, G.T., Hilton, N.Z., \& Rice, M.E. (1993). Patients admitted to psychiatric hospital: Presenting problems and resolution at discharge. Canadian Joumal of Behavioural Science, 25. 267-285.

Hatfield, A. B. (1987). Systems resistance to effective family coping. In A.T. Meyerson (Ed.), Barriers to treating the chronic mentally ill (pp. 51-62). San Francisco: Josey Bass.

Hodgins, S. (1996). The major mental disorders: New evidence requires new policy and practice. Canadian Psychology, 37, 95-111.

Kaus, M. (1992). The end of equality. New York: Basic Books.

Krueger, R.A. (1994). Focus groups: A practical guide to applied research (2nd ed.). Newbury Park, CA: Sage Publications.

Lamb, R.H. (1984). The homeless mentally ill. Washington, DC: The American Psychiatric Association.

Lieberman, A.A., \& Test, M.A. (1987). Health care practices and health status of the mentally ill in the community. Health and Social Work, 12, 29-37.

Lord, J., Schnarr, A., \& Hutchison, P. (1987). The voice of the people: Qualitative research and the needs of consumers. Canadian Joumal of Communify Mental Health, 6(2), 25-36.

Macnaughton, E (1992). Mental health policy in Canada: The emergent picture. Canada's Mental Health, 40(1), 3-10.

Monroe-Blum, H., Boyle, M.H., Offord, D.R., \& Kates, N. (1989). Immigrant children: Psychiatric disorder, school performance, and service utilization. American Joumal of Orthopsychiatry, 59(4), 510-519.

Morgan, D.L. (1997). Focus groups as qualitative research (2nd ed.). Newbury Park, CA: Sage Publications.

Nelson, G., Hall, G.B., Squire, D., \& Walsh-Bowers, R. (1992). Social network transactions of psychiatric paticnts. Social Science and Medicine, 34, 433-445.

Nelson, G., Ochocka, J., Griffin, K., \& Lord, J. (1998). Nothing about me without me. American Joumal of Community Psychology, 26(6), 881-912.

Nettleton, S., \& Bunton, R. (1995), Sociological critiques of health promotion. R. Bunton, S. Nettleton, \& R. Burrows (Eds.), The sociology of health promotion (pp. 41-59). London: Routledge.

Page, S. (1980). Social responsiveness towards mental patients: The general public and others. Canadian Journal of Psychiatry, 25, 242-246.

Page, S., \& Day, D. (1990). Acceptance of the "mentally ill" in Canadian society: Reality and illusion. Canadian Joumal of Community Mental Health, 9(1), 51-60.

Pape, B., \& Church, K. (1987). Community reimvestment: Balancing the use of resources to 
support people with mental disabilities. Toronto: Canadian Mental Health Association (National).

Poertner, J. (1994). Popular education in Latin America: A technology for the north? International Social Work, 37, 265-275.

Prilletensky, I. (1992). Empowerment in mainstream psychology: Legitimacy, obstacles and possibilities. Canadian Psychology, 35(4), 358-374.

Rappaport, J. (1985). The power of empowerment language. Social Policy, 16, 15-21.

Rappaport, J. (1987). Terms of empowerment/exemplars of prevention: Toward a theory for community psychology. American Joumal of Community Psychology, 15(2), 121-148.

Rice, A. (1998). Focusing on strengths: Focus group research on the impacts of welfare reform. Paper presented at the XX International Symposium, Association for the Advancement of Social Work with Groups, Miami.

Rioux, M.H., \& Crawford, C. (1990), Poverty and disability: Toward a new framework for community mental health. Canadian Joumal of Community Mental Health, 9(2), 97-109.

Rossi, P.H., Wright, J.D., Fisher, G.A., \& Willis, G. (1987). The urban homeless: Estimating composition and size. Science, 235, 1336-1341.

Salzer, M. (1997). Consumer empowerment in mental health organizations: Concept, benefits and impediments. Administration and Policy in Mental Health, 24(5), 425-434.

Salzer, M.S., McFadden, L., \& Rappaport, J. (1994). Professional views of self help groups. Administration and Policy in Mental Health, 22, 85-95.

Saraceno, B., \& Barbui, C. (1997). Poverty and mental illness, Canadian Joumal of Psychiatry. $42,285-290$.

Severron, M. (1994). Adapting social work values to the corrections environment. Social Work, $39(4), 451-456$.

Shragge, E. (1997). Workfare ideology for a new underclass. Toronto: Garamond Press.

Sidell, N., Jones, L., Katz, J., \& Peberdy, A. (1997). "Introduction." In N. Sidell et al. (Eds.), Debates and dilemmas in promoting health (pp, 1-3). London: MacMillan.

Spaniol, L., \& Zipple, A. (1986). Families with a chronically mentally ill member: A review of the research findings, In J.P. Bowker \& A. Rubin (Eds.), Studies on chronic mental illness. Washington, DC: Council on Social Work Education.

Springer, J.H., Mars, J.H., \& Dennison, M. (1998). A profile of the homeless population. Prepared for the Homelessness Action Task Force, City of Toronto.

Thiede, M., \& Traub, S. (1997), Mutual influences of health and poverty. Social Science and Medicine, 45(6), 867-77.

Townsend, E. (1998). Good intentions overruled: A critique of empowerment in the routine organization of mental health services. Toronto: University of Toronto Press.

Trainor, J., Church, K., Pape, B., Pomeroy, E., Reville, D., Teftt, B., Lakaski, C., \& Renaud, L. (1992). Building a framework for support: Developing a sector-based policy for people with serious mental illness. Canada's Mental Health, 40(1), 25-29.

Trainor, J., \& Tremblay, J. (1992), Consumer/survivor businesses in Ontario: Challenging the rehabilitation model. Canadian Joumal of Community Mental Healsh, II(2), 65-71.

Trainor, J., Pomeroy, E., \& Pape, B. (1997). The knowledge resource base: Expanding our understanding of serious mental illness, Canadian Joumal of Community Mental Health, I6(1), 109-117.

Walsh-Bowers, R., \& Nelson, G. (1993). An empowerment approach to community support for consumer/survivors. Unpublished manuscript available from authors.

Wellman, B. (1979). The community question. American Joumal of Sociology, 84, 1201-1231.

Wellman, B. (1983). From social support to social network. Working papers, Centre for Urban and Community Studies, University of Toronto, Toronto, Canada.

Wellman, B., \& Wortley, S. (1988). Brother's keepers: Situating kinship relations in broader networks of social support. Working papers, Centre for Urban and Community Studies, University of Toronto, Toronto, Canada.

Whelan, C.T. (1993). The role of social support in mediating the psychological consequences of economic distress. Sociology of Health and Illness, 15, 86-101.

Wilson, M.E., Flanagan, S., \& Rynders, C. (1999). The friends program: A peer support group 


\section{CANADLAN JOURNAL OF COMMUNITY MENTAL HEALTH}

model for individuals with a psychiatric disability. Psychiatric Rehabilitation Joumal, 22, 239-246.

World Health Organization. (1979). Schizophrenia: WHO Sudy shows that patients fare better in developing countries. Geneva: Author. 